\title{
Notas sobre o estatuto da morte na concepção freudiana de vida ${ }^{1}$
}

\author{
Notes on the status of death in the Freudian conception of life
}

\section{Pedro Fernandez de Souza*}

Resumo: Este artigo tenta compreender o estatuto da morte dentro da concepção de vida que se pode depreender das teorizações freudianas. Para isso recorremos a uma leitura comparativa entre dois momentos fundamentais da obra de Freud: o empreendimento metapsicológico (com destaque ao artigo sobre as pulsões, de 1915) e a publicação, em 1920, do Além do princípio de prazer. Verificamos que, em linhas gerais, as características mais essenciais com que a vida é descrita mantêm-se as mesmas em ambos esses momentos; o que mudou foi o estatuto conferido à morte nessa concepção, que de limite lógico e externo passou a ser origem e finalidade da vida. Notamos, outrossim, que a incorporação da morte no seio da vida não se deu no vazio, mas que Freud só a perfez ao se debruçar sobre hipóteses que marcavam presença em seu pensamento já antes de 1920, num processo de contínua reelaboração teórica.

Palavras-chave: Freud; Pulsão; Vida; Morte; Psicanálise

Abstract: This article aims to comprehend the status of death within the conception of life that one can infer from Freudian theorizations. To this end, we resorted to a comparative reading between two fundamental moments of Freud's oeuvre: the metapsychological project (with emphasis on the 1915 article on drives) and the publication, in 1920, of Beyond the pleasure principle. We verified that, in general, the most essential characteristics with which life is depicted remain the same in both of these moments; what changed was the status conferred to death in this conception, which from a logical and external limit became life's origin and finality. We noted thereto that the incorporation of death into the bosom of life did not arise in a vacuum, but rather that Freud has accomplished it as he dwelled on hypotheses that were present in his thinking even before 1920, in a process of continuous theoretical re-elaboration.

Key-words: Freud; Drive; Life; Death; Psychoanalysis

"Mas de graça é, como se sabe, apenas a morte". Tal a frase com que Freud introduz jocosamente as consequências do processo de divisão do eu, menos de dois anos antes de seu próprio falecimento. O ditado diz que para tudo nesta vida há um preço, exceto o

\footnotetext{
${ }^{1}$ Este artigo só foi possível em virtude do financiamento da Fundação de Amparo à Pesquisa do Estado de São Paulo (FAPESP) (processo no 2018/10320-6). Agradeço também à leitura atenta e às orientações sempre benfazejas de Janaina Namba, sem cujos comentários este artigo não viria à luz.

${ }^{2}$ FREUD, Die Ichspaltung im Abwehrvorgang, 60.
}

* Mestrando em Filosofia da Psicanálise pela Universidade Federal de São Carlos, São Carlos, SP. E-mail: pedrofsouza@gmail.com ORCID: https://orcid.org/0000-0002-7109-8469 
evento que lhe dá o seu único fim. Viria a morte, contudo, de forma absolutamente gratuita para o organismo vivo, de acordo com a própria concepção freudiana de vida? Quando se lê o ensaio hoje centenário em que as chamadas pulsões de morte foram trazidas a lume, temse a impressão de que mesmo a morte cobra um alto custo a quem deseja chegar até ela.

Este texto terá como objetivo compreender o estatuto da morte dentro da concepção freudiana de vida. Para isso trilharemos um caminho comparativo, buscando compreender, primeiramente, a concepção de vida que subjaz à "primeira” teoria das pulsões, para em seguida avaliar as possíveis mudanças operadas por Freud nessa teoria com a publicação do seu Além do princípio de prazer, em 1920. Focar-nos-emos em princípio nas definições expostas no artigo metapsicológico de 1915 sobre as pulsões, atentando-nos ao papel porventura exercido pela morte nos ínterins da sua argumentação.

Os cinco trabalhos metapsicológicos se iniciam, não em vão, com o artigo denominado Pulsões e destinos da pulsão (Triebe und Triebschicksale). Se na empreitada metapsicológica uma formalização sistemática da teoria psicanalítica parece constar enquanto objetivo delineador de todos os textos, nada mais razoável do que iniciar tal formalização como que de baixo para cima, do seu conceito mais basal: o conceito de pulsão.

O parágrafo que abre o ensaio explicita muito bem o terreno pantanoso em que Freud se embrenha: o das fundações da sua teoria. Os conceitos de base (Grundbegriffe) de uma teoria, argumenta Freud, não devem ser rígida e claramente definidos. Ao contrário: “eles devem a princípio carregar consigo um certo grau de indeterminação”. É sobre esses conceitos espinhosos que Freud discorrerá em sua teorização, sobretudo nos três primeiros artigos: as pulsões, a repressão, o inconsciente. Por que, então, o local privilegiado da pulsão? Pois todo o restante da exposição teórica dependerá de uma definição rigorosa dela.

Como confessa Freud, "um tal conceito de base convencional, atualmente ainda bastante obscuro, do qual nós na Psicologia não podemos, porém, prescindir, é o de

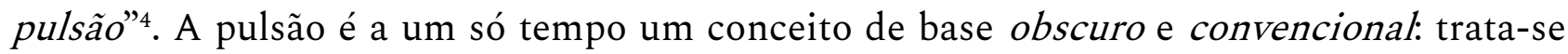
de uma convenção que participa da fundação mesma da teoria e cujo contorno epistêmico Freud doravante curará de delimitar.

Essa delimitação parte da fisiologia e do seu conceito de estímulo (Reiz): um estímulo que provém de fora incita o organismo a reagir, a livrar-se dele, coisa que ocorre mediante uma ação que retira o organismo do campo de influência do estímulo. Essa ação,

\footnotetext{
${ }^{3}$ FREUD, Triebe und Triebschicksale, 210.

${ }^{4}$ FREUD, id., 211.
} 
assim, chamada genericamente por Freud de fuga (Flucht), se dá também visando ao fora. “Como se relaciona, então, a 'pulsão' com o 'estímulo’? Nada nos impede de subsumir o conceito de pulsão ao de estímulo: a pulsão seria um estímulo para o psíquico" ${ }^{5}$. A pulsão, conceito que se finca diretamente na fisiologia: um estímulo (para o) psíquico.

Mas há duas principais diferenças entre estímulo e pulsão que deixam muito claras as especificidades do conceito psicanalítico. Em primeiro lugar, enquanto um estímulo vem de fora, a pulsão vem do exato oposto: "o estímulo da pulsão (Triebreiz) não advém do mundo externo (Außenwelt), mas sim do interior do próprio organismo. Por isso também, ele opera de forma diferente no anímico e exige outras ações para a sua eliminação"6. Assim, a pulsão não é somente um estímulo, mas um estímulo que acossa desde dentro. Em segundo lugar, enquanto o estímulo opera "como um golpe singular (ein einmaliger Stoß)” e, portanto, pode ser suprimido “através de uma ação eficaz singular”, “a pulsão, por sua vez, nunca atua como uma força de golpe momentânea (Stoßkraft), mas sempre como uma força constante (konstante Kraft)" sim do interior do corpo, de nada adianta uma fuga contra ela”. Esses estímulos pulsionais, aliás, merecem um nome mais adequado: necessidade, e "o que suspende (aufhebt) essa necessidade é a 'satisfação"'.

Pode-se desde já tecer um esquema do funcionamento de um organismo vivo segundo Freud, tendo como conceito-chave o de pulsão: num organismo estão diferenciados um dentro e um fora, e ambos são considerados por Freud como fontes de estímulos. Os estímulos externos são mais simples: são singulares, unitários, e requerem uma ação igualmente singular para serem evitados; os estímulos pulsionais, por outro lado, as ditas necessidades corpóreas, não são singulares, mas sim constantes, e uma fuga é completamente ineficaz defronte a eles. Tudo o que o organismo pode fazer é suspender ou anular ou revogar essas necessidades mediante a sua satisfação; aqui o verbo empregado por Freud é aufheben, o que não nos parece isento de significação: não se trata de fugir inteiramente da estimulação perturbadora, mas tão-somente de suprimi-la temporariamente, pois que a pulsão, sendo uma força constante (konstante Kraft), não deixará de voltar a importunar o organismo.

O organismo, portanto, é uma unidade cuja função principal é reagir a esses estímulos, sejam eles advindos de fora, sejam advindos de dentro. É aqui que a concepção freudiana de vida é explicitada de forma muito clara. Um pouco adiante Freud admite: para compreender os fenômenos psicológicos, "nós trazemos ao nosso material empírico não apenas certas convenções enquanto conceitos de base, mas também nos utilizamos de

\footnotetext{
${ }^{5}$ FREUD, ibid.

${ }^{6}$ FREUD, id., 211-2.

${ }^{7}$ FREUD, id., 212.

${ }^{8}$ FREUD, ibid.
} 


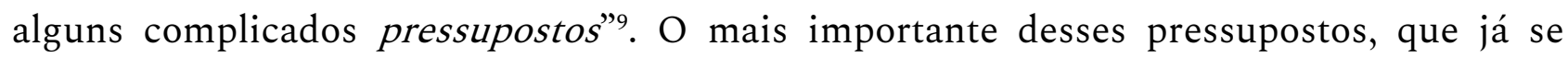
encontrava entranhado na argumentação freudiana anterior, é de natureza biológica, isto é, concerne à vida enquanto tal, e reza que "o sistema nervoso é um aparelho (Apparat) ao qual é conferida a função de eliminar os estímulos que lhe chegam, de rebaixá-los ao menor nível possível, ou, se isso porventura fosse possível, ele [o aparelho] gostaria de manter-se totalmente isento de estímulos (reizlos)" ${ }^{10}$. Assim, de um modo geral, a tarefa do sistema nervoso (e da vida, grosso modo), é o de superar ou vencer os estímulos, a Reizbewältigung ${ }^{11}$.

Ora, a vida em Freud não é senão conflito, e o organismo aí é conceituado enquanto um verdadeiro campo de batalha. O vocabulário então empregado não deixa dúvidas: o Reiz é um Stoß, um golpe, uma pancada; o Trieb, tipo especial de Reiz, é uma konstante Kraft, uma força constante; e é numa espécie de batalha tanto contra (gegen) o fora quanto contra o dentro que o organismo se empenha desde sempre, em sua tentativa de bewältigen (superar, vencer, dominar) os estímulos que o hostilizam de todos os lados ${ }^{12}$. Definitivamente, a vida não é algo gratuito para Freud. Deixemos notado, ademais, que Freud cogita a procura de um término total da estimulação, de forma que o organismo viesse a ser reizlos. O zero de estímulo aparece aqui enquanto limite lógico do pressuposto biológico sobre o qual se erige a teoria freudiana das pulsões: o chamado princípio de

\footnotetext{
${ }^{9}$ FREUD, id., 213.

${ }^{10}$ FREUD, ibid.

${ }^{11}$ Sobre o termo Bewältigung, oriundo do verbo bewältigen - e sobre outros termos alemães importantes -, remetemos o leitor ao Dicionário comentado do alemão de Freud, de Luiz Hanns. Aí se indica que bewältigen pode ter várias conotações, por vezes diversas das que o verbo português dominar pode ter. Destaco as seguintes: "superar", "dar conta de uma tarefa", "enfrentar algo avassalador"; copio aqui, ainda, a fim de deixar manifesta a dimensão em que nos encontramos, a pequena lista de correlatos, derivados e parentes etimológicos presentes no dicionário de Hanns: “Gewalt. violência, força; gewaltig. incrível, enorme, intenso, muito; überwältigend: avassalador, grandioso, soberbo; vergewaltigen: estuprar; walten: reinar, ser soberano" (HANNS, Dicionário comentado do alemão de Freud, 176-182).

${ }^{12}$ Registremos aqui, en passant, que o mesmo vocabulário, digno de uma ars bellica, se encontra também em certas descrições da técnica analítica. Em 1912, em seu artigo sobre o conceito de inconsciente, após postular a existência de pensamentos inconscientes, Freud diz que, ao contrário do que se esperava, muitos desses pensamentos (os pertencentes ao sistema inconsciente, não ao pré-consciente) não são despossuídos de força (Kraft), mas são tão fortes (stark) quanto se pode esperar. Esse jogo psíquico de forças se mostra na resistência (Widerstand) que o paciente opõe ao tratamento, sinal de que há uma defesa $(A b w e h r)$ em operação se contrapondo à emergência do material inconsciente. O que se deve fazer quanto a essa defesa? A palavra freudiana é clara: ela deve ser vencida (,... das deutliche Gefühl einer Abwehr, die bewältigt werden muß..."). Ora, não pode ser coincidência que o verbo utilizado por Freud seja esse. Assim como a função do aparelho anímico é de superar, dominar ou vencer (bewältigen) os estímulos que lhe chegam, também a tarefa do analista é de vencer, dominar ou superar (bewältigen) a defesa que se manifesta no tratamento como resistência (FREUD, Einige Bemerkungen über den Begriff des Unbewusstes in der Psychoanalyse, 433 e 435).
} 
constância, de acordo com o qual a função do organismo é livrar-se dos estímulos e manter-se estimulado o mínimo possível.

Duas das características essenciais da pulsão que já descrevemos terão ainda consequências importantes para nós: o fato de a estimulação pulsional advir do interior do corpo do organismo; e o chamado princípio de constância, que recém-definimos. A partir do primeiro desses caracteres, tem-se a clássica definição da pulsão

enquanto um conceito-limite (Grenzbegriff) entre anímico e somático, enquanto representante psíquico (psychische Repräsentant) dos estímulos que provêm do interior do corpo e chegam à alma, enquanto uma medida de exigência de trabalho (ein Maß der Arbeitsanforderung) que é imposta ao anímico em consequência de sua conexão (Zusammenhang) com o corpóreo ${ }^{13}$.

Demarcações importantes: o estímulo corpóreo, para chegar à alma, transpõe uma espécie de limite; ao fazê-lo, ali chega representado (delegado, sub-rogado) enquanto estímulo pulsional. Alma e corpo formam uma espécie de con-texto ou co-nexão (Zusammenhang), uma espécie de nó ou nexo. Esse nexo, pode-se dizer, constitui o organismo enquanto tal. Trata-se, assim, de um conceito-limite, que marca o limite após cuja transposição assoma para a alma o trabalho que dela é exigido em virtude dessa conexão imanente com o corpo. Ora, esse limite não é apenas um limite constituinte do organismo mesmo, mas também da própria teoria: conhecer a fonte orgânica da pulsão, diz Freud, não é tarefa imprescindível na investigação psicológica, "o estudo das fontes pulsionais já não compete à psicologia"14. Para a psicanálise o que está em jogo é essa aparição, mediante representação, do somático no anímico. Eis o estatuto fundamental do conceito de pulsão: ela marca uma delimitação ontológica inerente ao organismo como conceituado pela psicanálise, que se espelha numa delimitação epistemológica da própria teoria psicanalítica ${ }^{15}$.

Nós vimos: a principal tarefa do organismo é dominar esses estímulos. Essa Reizbewältigung, porém, não se manifesta de qualquer maneira para o organismo; ele é guiado, antes, por uma série temporal de sensações bastante específicas. "A atividade dos aparelhos anímicos (Seelenapparate), mesmo dos mais desenvolvidos, se sujeita ao

\footnotetext{
${ }^{13}$ FREUD, Triebe und Triebschicksale, 214.

${ }^{14}$ FREUD, id., 216.

${ }^{15}$ Cf., sobre isso, o Prefácio à terceira edição dos Três ensaios sobre a teoria sexual, escrito em 1914, onde Freud enfatiza a "deliberada independência" com respeito à "pesquisa biológica" (die vorsätzliche Unabhängigkeit von der biologischen Forschung) que faz parte de seu próprio trabalho de investigação das pulsões sexuais. Nota-se aí o caráter fronteiriço dessa pesquisa psicanalítica: Freud reconhece a dimensão biológica da sexualidade, mas o que ele se propõe averiguar, "através da técnica da psicanálise” (durch die Technik der Psychoanalyse), é a sua importância psicológica, qual seja, seus efeitos na vida da alma, no plano representacional da existência do organismo (FREUD, Drei Abhandlungen zur Sexualtheorie, 30).
} 
princípio de prazer, isto é, ela é automaticamente regulada por sensações da série prazerdesprazer"16. Essas sensações "reproduzem a maneira com que se cumpre o domínio de estímulos (Reizbewältigung)"17: "as sensações de desprazer têm a ver com o aumento do estímulo; as de prazer, com a sua redução" ${ }^{18}$. Elas são, portanto, a manifestação, no e para o organismo, desse princípio que rege o seu agir: é função do organismo se livrar dos estímulos internos; ao seu acréscimo é correlato um incômodo (o desprazer) que preme o organismo a sair da situação molesta - o resultado dessa liberação, ainda que momentânea, é o ganho de prazer.

Tal a aparição, neste artigo, do famígero princípio de prazer, que fora apresentado ao mundo na Interpretação dos Sonhos quinze anos antes enquanto princípio de desprazer. Atentemo-nos às palavras empregadas nessas passagens. Aí se diz muito claramente que a atividade do aparelho psíquica é automaticamente regulada pelo princípio de prazer, e que este consiste numa série temporal de sensações prazerosas e desprazerosas. A vida, nessa definição, está colada a essas sensações básicas, que definem e determinam as ações e reações de cada vivente. Sendo as pulsões uma força constante e uma medida de exigência de trabalho que aspira imediatamente à descarga motora, caberá ao organismo premido por elas dominá-las e prorrogar sua satisfação, mesmo que parcialmente.

Assim, se o organismo a princípio alucinava a primeira satisfação das exigências pulsionais sempre que estas voltavam a se fazer presentes, submetido aos chamados princípios (psíquicos) primários, como se pode ler no artigo seminal de $1911^{19}$, é sua tarefa capital abandonar o funcionamento primário de seu aparelho anímico e, a partir das áridas imposições advindas da realidade externa, substituir o princípio de prazer pelo princípio de realidade. Essa "substituição" não é completa, dado que a tendência básica do organismo nunca deixará de ser a obtenção de prazer, e trata-se, pois, de uma instauração como que à força, em cujo decorrer tornam-se patentes as contradições inerentes entre o dentro (as pulsões) e o fora (a realidade) do organismo, ou entre o Prazer e o Real, se assim podemos expressar-nos. Com efeito, como se pode ler tanto em 1911 quanto em 1925²0, o desenvolvimento do aparelho anímico é uma dura vereda através da qual o eu-prazer inicial (Lust-Ich) deve metamorfosear-se num ulterior eu-realidade (Real-Ich): enquanto aquele vive numa espécie de mundo binário, em que se incorpora o bom (prazeroso) e se rejeita o mau (desprazeroso), este tem como atribuição se assegurar de que as representações por ele percebidas são reais, isto é, de que elas existem. Trata-se de toda a batalha de instaurar os chamados processos (psíquicos) secundários numa lenta e árdua pedagogia da pulsão.

\footnotetext{
${ }^{16}$ FREUD, Triebe und Triebschicksale, 214.

${ }^{17}$ FREUD, ibid.

${ }^{18}$ FREUD, ibid.

${ }^{19}$ FREUD, Formulierungen über die zwei Prinzipien des psychischen Geschehens, 231.

${ }^{20}$ FREUD, Die Verneinung.
} 
Esse desenvolvimento pulsional se organiza de acordo com um quadro bastante específico de possíveis destinos da pulsão (Triebschicksale), para voltar ao nosso artigo metapsicológico de 1915. Somente quatro desses destinos são vislumbrados por Freud: a transformação (Verkehrung) no contrário, a volta até a própria pessoa, a repressão (Verdrängung) e a sublimação. Quanto aos dois últimos, Freud neste artigo não se pronuncia - da repressão ele tratará no próximo artigo metapsicológico (ao qual recorreremos em breve); o artigo a respeito da sublimação, pensa-se, foi perdido. Os exemplos aduzidos de "volta até a própria pessoa" são a transformação de sadismo em masoquismo e do prazer de ver no de ser visto.

Ora, o que ocorre em todos esses casos de destinos e metamorfoses de pulsões? Eles estão sempre submetidos a um horizonte prévio de polaridades. Expliquemo-nos tomando como exemplo a transformação do sadismo em masoquismo. O sadismo, argumenta Freud, é a execução de violência e poder contra outra pessoa, tomada aqui enquanto objeto tanto da ação quanto da pulsão. Renuncia-se então a essa pessoa, e a pulsão sofre a volta à própria pessoa. Agora é em si mesmo que se deve exercer violência e poder, o que significa que o objetivo da pulsão, de ativo, passou para passivo. O terceiro e último passo na concretização do masoquismo é a procura de um novo objeto da pulsão, que doravante exercerá o papel de sujeito da ação ${ }^{21}$. Complexo quadro temporal das relações entre os múltiplos elementos lógicos e antitéticos da metamorfose pulsional: sujeito e objeto da ação; sujeito e objeto da pulsão; atividade e passividade; o dentro e o fora. Todas essas dualidades se entrecruzam, formando enquadramentos temporários de atuações pulsionais: num primeiro momento o sujeito da pulsão é também o sujeito da ação, mas num segundo momento ele se torna o objeto da ação; a princípio a meta pulsional é ativa e o fora é quem tem de sofrer a ação mediante a qual a pulsão será satisfeita, mas num segundo momento, tendo a meta pulsional se tornado passiva, a ação vem do fora e é o organismo quem deve sofrê-la.

A conclusão dessa homogeneidade formal presente em todo destino das pulsões é fundamental: "a vida anímica em geral é governada por três polaridades, as oposições entre: sujeito (eu) - objeto (mundo externo); prazer-desprazer, ativo-passivo" 22 . Esse quadro tríptico de polaridades nos parece sobremodo fundamental quando se leva em consideração que Freud finaliza o artigo invocando-o uma vez mais e dando-lhe destaque textual: "nós podemos sublinhar, sumarizando, que os destinos de pulsão consistem, no essencial, em que as moções pulsionais são submetidas às influências das três grandes polaridades que governam a vida da alma" ${ }^{23}$. Ora, o que se vê aqui é a delimitação de um horizonte preliminar de negatividades no qual (e somente no qual) a vida anímica se

\footnotetext{
${ }^{21}$ FREUD, id., 220.

${ }^{22}$ FREUD, id., 226.

${ }^{23}$ FREUD, id., 231.
} 
desenrola; a pulsão, conceito-limite de base do edifício teórico analítico, representa psiquicamente a exigência interna e corporal de trabalho imposta ao organismo, e o modo com que este irá executar tal tarefa se enquadrará sempre nesse panorama precedente de polaridades. Trata-se de um campo de negatividades imanente à vida e ao qual se submete todo trâmite de moções pulsionais. Não é exagero ver aqui o estabelecimento de uma tabela freudiana de categorias, que se limita aos destinos das pulsões e tão-somente a eles. O organismo reage à pressão pulsional que vem de dentro? Pois bem, ele não tem escolha, só poderá fazê-lo se arranjando nesse quadro primário de oposições lógico-ontológicas: sujeito e objeto; fora e dentro; ativo e passivo.

O complexo e usual caso da repressão (Verdrängung) - que, aliás, é descrito com o mesmo vocabulário belígero que destacamos acima ${ }^{24}$ - não se dá num horizonte distinto; as peças estão somente ligeiramente deslocadas, pensamos. Exercendo a pulsão um Drang (impulso ou pressão) específico e sendo a situação de forma tal que nenhuma outra escapatória haja, a solução é $z u$ verdrängen (reprimir) essa moção pulsional. A pulsão preme, faz pressão; o organismo, oprimido pela áspera realidade e impossibilitado de satisfazer às suas exigências diuturnas, a reprime, exerce contra ela uma repressão, a partir da qual a representação que a representa (Vorstellungsrepräsentanz) se torna e há de permanecer inconsciente. Assim é criado, com a repressão, um novo fora para o organismo, um fora que é concomitantemente o seu dentro inacessível (o inconsciente reprimido).

Essa exterioridade do interno só complica a tabela de categorias antes apresentadas, visto que o organismo terá doravante de lidar com dois foras ${ }^{25}$, sendo que contra um deles, o inconsciente reprimido, nenhuma fuga é eficaz. E é justamente no sentido da fuga que o organismo se comporta quando, por exemplo, projeta para o fora, para o mundo exterior, um conteúdo que lhe é interno, para que se possa assim fugir dele ${ }^{26}$; ou mesmo quando "o eu abdica do desejo de dormir, porque se sente incapaz de inibir as moções reprimidas que durante o sono se tornaram livres; em outras palavras, que renuncia ao sono, porque teme

\footnotetext{
${ }^{24} \mathrm{O}$ ensejo para a ocorrência de uma repressão é que uma moção pulsional "se choque com resistências (auf Widerstände stößt) que desejam torná-la inoperante”, sendo o verbo stößen aparentado com o Stoß (o choque, o golpe) que é o estímulo; a condição de uma repressão é "que o motivo de desprazer obteve um poder mais forte (eine stärkere Macht) do que o prazer da satisfação"; e a repressão, que luta contra uma força constante, se torna, por consequência, "um incessante dispêndio de força” (einen anhaltenden Kraftaufwand). FREUD, Die Verdrängung, 248, 249, 253.

${ }^{25}$ Nesse sentido o inconsciente, o mundo interno do sujeito, não é muito simplesmente o dentro de que fala Freud no artigo sobre as pulsões. Esse dentro é o interior do corpo, de onde emanam as moções pulsionais, origem orgânica e isenta de representações das urgências naturais do organismo; o inconsciente reprimido, por sua vez, é um conjunto de representantes pulsionais desligados de seus afetos originários e que, graças às leis mesmas do sistema inconsciente, premem por tornar-se conscientes.

${ }^{26}$ FREUD, Metapsychologische Ergänzung zur Traumlehre, 424.
} 
os próprios sonhos”27. Nós evocamos esses outros trechos dos artigos metapsicológicos ${ }^{28}$ para deixar claro que, mesmo no caso fundamental da repressão e mesmo no caso dos sonhos, é sob as mesmas três polaridades que os processos se enquadram, pois no fundo sempre se trata, do sugar do bebê ao sublimar do adulto, de diferentes destinos das pulsões. Essa tabela freudiana de polaridades lógico-ontológicas, nós pensamos ser ela o quadro de categorias primárias às quais está submetida a vida em geral. Segundo Freud, um organismo vivo, do mais simples ao mais complexo, é uma unidade (um in-divíduo, Individuum $)^{29}$ para o qual se diferenciam um dentro e um fora e cuja função é receber e metabolizar os estímulos que lhe advêm tanto de um quanto de outro, comportando-se passiva ou ativamente nessa empreitada e sempre sendo posto num dos polos da dualidade sujeito-objeto.

Contudo a vida, ao se desenrolar no tempo sob o enquadramento das três polaridades, não o faz sem uma determinada finalidade. Após indicar a dualidade pulsional com a qual trabalha em 1915, qual seja, o dualismo entre pulsões egoicas (ou de autoconservação) e pulsões sexuais, Freud expõe a multiplicidade e parcialidade das pulsões sexuais que, de início, não buscam senão o chamado prazer de órgão (Organlust); é “somente após efetuada uma síntese” que "elas entram a serviço da função da reprodução, com o que elas se tornam então reconhecíveis enquanto pulsões sexuais" ${ }^{30}$. É aqui que se nota uma certa teleologia do exercício das pulsões, uma teleologia bastante delicada e em alguns sentidos insustentável, dado o caráter polimórfico, fragmentário e plástico que é essencial à pulsão em seus estágios pré-genitais ${ }^{31}$ e dado que o objetivo (Ziel) da pulsão é

\footnotetext{
${ }^{27}$ FREUD, id., 416.

${ }^{28} \mathrm{E}$ o fio condutor dos raciocínios constituintes dos artigos metapsicológicos restantes pode ser identificado da mesma forma. No artigo $O$ inconsciente, Freud cura de expor as leis que regem esse fora interior que se costumou denominar inconsciente, explicitando a enorme complexidade que a existência de uma tal exterioridade interna acarreta para a vida do indivíduo (cf., sobretudo, sua seção sobre as psicoses); em Luto e melancolia, por sua vez, tem-se a análise detalhista do estado melancólico em comparação com o enlutado, e toda a argumentação se centra na sua diferenciação a partir desse campo prévio de polaridades que fizemos destacar: é sempre trabalhando com as negatividades fora-dentro, eu (sujeito) - mundo exterior (objeto) e atividade-passividade que Freud distingue um estado do outro.

${ }^{29}$ Pode parecer estranha a constatação de um indivíduo enquanto unidade sob a pena freudiana, sendo que em psicanálise se fala muito amiúde das cisões do eu ou das diferenciações sistêmicas do aparelho psíquico. Em verdade não se trata de uma contradição: um indivíduo é uma unidade, que porém é constituída por suas partes; essas partes agem em conjunto, e o fato de se alojarem num mesmo indivíduo dá um sentido coletivo ao seu funcionamento. Do mesmo modo, por se tratar de um organismo, suas partes funcionais são seus órgãos. Para Freud, um desses órgãos é muito precisamente a própria alma, ou o aparelho anímico.

${ }^{30}$ FREUD, Triebe und Triebschicksale, 218.

31 Sobre isso, cf. SAFATLE, A teoria das pulsões como ontologia negativa, com cujos argumentos concordamos, mas do qual nos diferenciamos pois acreditamos haver uma teleologia na primeira teoria freudiana das pulsões, que, justamente por ser claudicante, pode ser capaz de mostrar quais são as contradições inerentes ao edifício teórico freudiano.
} 
sempre sua satisfação, isto é, o ganho de $\operatorname{prazer}^{32}$, mas ainda assim afirmada uma e outra vez por Freud. Não é em vão que, dois parágrafos antes, ele tenha evocado os ensinamentos da biologia, segundo os quais "não se há de equiparar a sexualidade às outras funções do indivíduos, pois suas tendências ultrapassam o indivíduo e têm como conteúdo a produção de novos indivíduos, isto é, a conservação da espécie (die Erhaltung der Art)"33. Entre o eu e a sexualidade há eterna contradição: para aquele, o indivíduo é tudo o que importa; para esta, ele "é um apêndice temporário e efêmero do quase-imortal plasma germinal" ${ }^{4}$.

O indivíduo é assim uma contradição encarnada ${ }^{35}$ : dentro de si premem forças que o constringem a sobreviver, mas isso apenas para que a espécie (da qual ele não passa de um apêndice passadouro) sobreviva. Notemos que nessa argumentação se manifesta uma fundamental primazia do universal sobre o particular. o universal (a espécie) é sempre mais importante que o particular que a representa (o indivíduo). No final das contas a vida quer se reproduzir - e nada além disso. A vida nada quer saber dos indivíduos por meio dos quais a vida vive. A partir da criação de novos indivíduos, mais ou menos diferentes entre si, ela deseja a reprodução da identidade de si mesma. Por mais tortuosos que sejam os meandros da vida, todo o seu percurso visa a essa repetição. Ora, é justamente aqui que a morte faz sua aparição, bastante tímida e lateral, na concepção freudiana de vida: o indivíduo é zeitweilig (temporário), enquanto o plasma germinal é quasi unsterblich (quase-imortal). Atenção seja dada ao caráter adjetival dessa aparição: trata-se de um limite lógico, que novamente se faz presente na argumentação somente como sombra do que

\footnotetext{
${ }^{32}$ Cf. o que diz García-Roza a respeito disso: “'O objetivo (Ziel) de uma pulsão', escreve Freud em A pulsão e seus destinos, 'é sempre a satisfação'. É portanto em termos de satisfação que temos de compreender a pulsão e não em termos de uma finalidade que lhe seja transcendente. Prazer nada tem que ver com reprodução. O caráter prazeroso ou satisfatório de um comportamento sexual não está subordinado à reprodução nem pode ter nesta seu princípio explicativo. Admitir essa subordinação é fazer um reducionismo grosseiro e, ao mesmo tempo, denegador da pulsão" (Freud e o inconsciente, 107). Concordamos inteiramente com isso: não intentamos reduzir o conceito de pulsão ao de reprodução, mas sim investigar a dimensão biologicamente teleológica de que ela participa.

${ }^{33}$ FREUD, Triebe und Triebschicksale, 217-8.

${ }^{34}$ FREUD, id., 218.

${ }^{35}$ Relembremos que um ano antes, em seu artigo sobre o conceito de narcisismo, Freud utilizara palavras quase idênticas ao elencar justificações biológicas para a diferenciação entre uma libido objetal e uma libido egoica. Aí, lê-se que "o indivíduo realmente leva uma existência dupla (eine Doppelexistenz)", ele é a um só tempo o fim, o escopo de si mesmo (sein Selbstzweck) e o elo de uma corrente (Glied einer Kette) à qual ele serve exercendo sua função sexual; esta, ainda que lhe surja enquanto um propósito pessoal, nada mais é do que a função que assegura a continuidade da espécie - sob esse ponto de vista, o indivíduo não passaria de um apêndice ou acessório (Anhängsel) do plasma germinal (Keimplasma). Freud ainda comenta: é a este plasma, a essa substância talvez imortal que ele põe suas forças à disposição, apenas para conseguir, como um prêmio de consolação, um pouco de prazer (dem es seine Kräfte gegen eine Lustprämie zur Verfügung stelltt). Vê-se o nobre estatuto do prazer nessa concepção: mera recompensa secundária pelo exaurimento de forças na consecução de uma função universal que o ultrapassa enquanto indivíduo particular. FREUD, Zur Einführung des Narzissmus, 143.
} 
realmente está em questão. O múltiplo e diverso há de morrer para que o Idêntico se reproduza - é aí que a morte aparece, e em nenhum outro lugar do raciocínio freudiano. Ela nessa argumentação não passa de um elemento essencial para que se cumpra a essencial teleologia da vida.

Parece-nos claro que, nesse momento da teorização freudiana, a vida é um ponto pacífico, ela aí é tida como algo muito obviamente dado: a vida é o oposto de harmonia, e caminha sempre naquele campo preliminar de polaridades, visando incessantemente ao estabelecimento de uma harmonia inalcançável. No conceito de vida, imanente a ele, está o conceito de mortalidade: os indivíduos são mortais e não podem estender sua existência ad aeternum. É somente aí que a morte é conceituada, então, por Freud, enquanto limite lógico necessário ao exercício atribulado, pacificamente atestado, da vida. Ela participa negativamente da vida, a define e a limita por fora, como que pelo seu avesso. Em 1915, por mais mórbidos que por vezes se façam os raciocínios freudianos, é somente do florilégio exuberante da vida que eles tratam.

Mas julgamos haver duas arestas entremeadas nessa argumentação, e é a partir delas que passaremos ao Além do princípio. Uma concerne à origem da vida, e a outra ao estatuto da realidade na dinâmica pulsional do organismo.

Sobre a origem da vida, Freud em 1915 se limita a manter-se tácito, e é apenas lateralmente que a questão é abordada. Ao reiterar a inevitabilidade dos estímulos orgânicos internos, a conclusão é que as pulsões "colocam exigências muito mais elevadas ao sistema nervoso"; conseguintemente, "são as pulsões, e não os estímulos externos, os verdadeiros motores do progresso que levaram o sistema nervoso, tão infinitamente eficiente, ao seu atual nível de desenvolvimento" ${ }^{36}$. A estimulação interior, portanto, é o que incita o organismo a desenvolver seus modos de metabolização. Nesse momento argumentativo, o fora é muito menos exigente que o dentro, e, caso não houvesse pulsão, a vida não se teria tornado tão complexa como é hoje. Mas a sentença seguinte do texto inverte totalmente esse privilégio, ou melhor, vislumbra a possibilidade dessa inversão: "naturalmente, nada se contrapõe à suposição de que as próprias pulsões, ao menos em parte, sejam sedimentações dos efeitos de estímulos externos, os quais no curso da filogênese exerceram efeito na substância viva, modificando-a" ${ }^{37}$. Ora, aqui é aventada a possibilidade de a pulsão, a força imanente à vida mesma, ser uma espécie de interiorização do fora. À vida seriam impostas, assim, para dentro de si, as forças que não lhe eram a priori internas.

\footnotetext{
${ }^{36}$ FREUD, Triebe und Triebschicksale, 213-4.

${ }^{37}$ FREUD, id., 214.
} 
E é dessa relação complexa com o fora que deriva uma diferenciação que Freud diz ser primária ao organismo. Sendo os estímulos externos evitáveis mediante fuga, e sendo impossível qualquer fuga diante dos estímulos internos, a ação muscular ganha enorme importância para a sobrevida do indivíduo: "a substância percipiente do ser vivo terá assim ganhado, na eficácia da sua atividade muscular, um ponto de referência (Anhaltspunkt) para diferenciar um 'fora' de um 'dentro"” ${ }^{38}$. Do fora se foge; do dentro, não: é a ação muscular que indica ao organismo, com suas consequências materiais, o que vem de dentro e o que vem de fora. Essa linha de raciocínio, apresentada logo no início do artigo, reaparecerá várias páginas depois, perto de seu fim, porém agora sob uma terminologia diferente. Após discorrer sobre as oposições entre amor e ódio, Freud afirma: “assim, a partir do eu-real inicial (anfänglichen Real-Ich), que diferenciou dentro e fora segundo um bom e objetivo traço distintivo, muda-se em um eu-prazer (Lust-Ich) purificado, que antepõe o caráter de prazer a todos os outros" 39 . Ora, tal afirmativa não pode senão chocarse com as hipóteses apresentadas em 1911 e 1925 e que há pouco fizemos destacar: aí se diz muito claramente que o eu-prazer inicial deve tornar-se, após o influxo da realidade externa, um eu-real. Em 1915, Freud se utiliza do mesmíssimo termo (Real-Ich) para se referir a uma fase primária do eu, anterior mesmo à instauração do eu-prazer. Tudo indica que o Real-Ich de 1911 e 1925, resultado do desenvolvimento do eu a partir das limitações materiais impostas pela realidade externa à satisfação imediata das exigências pulsionais, não é o mesmo Real-Ich de 1915: o Real de 1915 é algo muito mais primordial e originário, ele não diz respeito ao Real que se contrapõe ao Prazer e que limita o seu império, mas sim a algo prévio a esse império. Tratar-se-ia do contato mais primário da vida com o mundo em seu entorno, isto é, das primícias dessa relação conflituosa e perene.

É assim que, nesses dois momentos da letra freudiana de 1915, o Real mostra ser um verdadeiro ponto de tensão da concepção de vida então desenvolvida: ele, que parecia menos importante e cuja influência se faria notar somente após (ou durante) a resignação do império absoluto do Prazer, aparenta ser, no fim das contas, muito mais fundamental e primordial do que qualquer outro elemento da economia beligerante da vida.

\section{III}

Sabe-se bem: Freud inicia seu Além do princípio do prazer reafirmando a suposição adotada em psicanálise segundo a qual "o curso dos processos anímicos é automaticamente regulado pelo princípio de prazer" 40 (deixando bem claro que "o

\footnotetext{
${ }^{38}$ FREUD, id., 212.

${ }^{39}$ FREUD, id., 228.

${ }^{40}$ FREUD, Jenseits des Lustprinzips, 3.
} 
princípio de prazer deriva do princípio de constância” ${ }^{41}$, ou seja, que ele é uma espécie de manifestação, na ordem da vida, de um princípio físico) para, em seguida, expor uma série de fenômenos que urgem a teoria a admitir um nível do funcionamento anímico que se situe além desse princípio.

O primeiro desses fenômenos, cuja importância se fará monumental no decorrer do texto, é "a reação anímica frente ao perigo exterior" ${ }^{42}$, que em casos extremos recebe um nome que ecoa desde os prelúdios da teorização freudiana: trauma (Trauma). Qual fenômeno das chamadas neuroses traumáticas chama mais a atenção de Freud? Muito precisamente o sonho (Traum). Este, ao menos desde 1900, fora conceituado como uma realização (disfarçada) de desejos (reprimidos), demonstração privilegiada do modo mais primordial com que a alma metaboliza e elabora a estimulação que a acossa. O sonho faria de tudo para manter o indivíduo dormindo e sua função princeps seria a de guardião do sono. Os neuróticos traumáticos, entretanto, ao sonhar são levados novamente à situação do acidente que engendrou sua doença, e são acordados com novo assombro. "O doente estaria, por assim dizer, psiquicamente fixado no trauma”, e a vivência traumática o assediaria repetidas vezes durante o seu sono em virtude mesmo da "força da impressão"

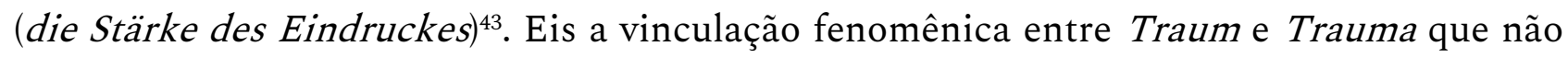
havia sido ainda conceituada por Freud: o sonho típico dessa classe de patologia não realiza desejos inconscientes; ele, antes, leva o indivíduo de volta a uma situação pesarosa, cuja força desmesurada deixou nele uma impressão aparentemente inapagável. Trata-se de uma repetição muito específica, que não é levada a cabo para evitar desprazer ou angariar prazer, como se era de esperar.

Da neurose traumática, Freud passa aos jogos infantis, ou melhor, a um jogo infantil muito específico, de seu neto de um ano e meio de idade. É o célebre caso da brincadeira do fort-da, em que o garotinho, ainda imperito para a palavra falada, lançava um carretel até onde a vista não alcançava para depois trazê-lo de volta, tudo isso sempre acompanhado primeiro por um $o-o-o-o$ (que se sabia ser um "fort", isto é, "embora" ou "que se foi”) e, em seguida, por um $d a$ (ou seja, “aí” ou “ali”). Essa brincadeira era uma reação ao fato de sua mãe o deixar sozinho por várias horas: "esse era, pois, o jogo completo, desaparecer e regressar" ${ }^{44}$. Com o jogo, a criança encenava o desaparecimento e o reaparecimento da mãe. Freud aí diagnostica também a tendência de se apoderar, se apropriar da vivência: se originalmente a criança experimenta passivamente as idas e vindas da mãe, no brincar ela as reencena ativamente, "ela mesma põe em cena" (es... selbst ins Szene setzte) a situação durante a qual antes era passiva. Pode-se notar aqui, pois, uma transformação do passivo em ativo que não se relaciona de forma simples e direta com o

\footnotetext{
${ }^{41}$ FREUD, id., 5.

${ }^{42}$ FREUD, id., 8.

${ }^{43}$ FREUD, id., 10.

${ }^{44}$ FREUD, id., 12.
} 
ganho de prazer. Sente-se prazer com o retorno da mãe? Sim, porém aquilo a que nos atenta Freud é o eventual fato de somente a primeira parte do jogo, a da desaparição, ser executada repetidas e repetidas vezes. Ora, tal fenômeno é precisamente aquele que não dá prazer ao garoto- uma vez mais é um evento de carga fenomenológica negativa que é repetido, tal como no sonho dos doentes traumáticos. A questão toda se centra, então, nesse selbst, nesse si mesmo que assoma na descrição freudiana de um indivíduo que, passivo, recebe a impressão de uma vivência desagradável e, numa encenação posterior, tenta se apropriar ativamente dela. Selbst este que faz presença também numa nota de rodapé fundamental e quase despretensiosa: durante as longas solidões impostas pela ausência da mãe, a criança "havia encontrado um modo de, ela mesma, fazer-se desaparecer" - tendo descoberto a sua imagem (Bild) num espelho, ela se agachava, de modo a fazê-la ir embora (so daß das Spiegelbild „fort" war ${ }^{45}$. Eis o indivíduo passando por sua absoluta solidão e descobrindo o seu duplo imagético no espelho - apenas para fazê-lo esvanecer, tal qual antes esvanecera a mãe. É nesse sumir-se de si mesmo, parece-nos, que o si mesmo enquanto atividade pode emergir.

As duas outras classes de fenômenos contrários ao império do Prazer, resumamo-las para não nos alongarmos: trata-se da repetição em ato, no decorrer da transferência analítica, de eventos que em sua origem não puderam ser prazerosos. São "reproduções de indesejada fidelidade" de uma parte obnubilada da vida sexual infantil, que são efetuadas à revelia do paciente ${ }^{46}$. À repetição transferencial, segue a lista de pessoas ditas normais (em linguagem freudiana: que não transpõem seus conflitos em sintomas neuróticos) que seguem repetindo experiências dolorosas, por vezes de forma vergonhosa ou assombrosa. Freud aqui evoca o nietzschiano "eterno retorno do mesmo" 47 - e o acento deve recair aqui nesse mesmo, nesse idêntico que insiste em retornar de forma demoníaca na vida das pessoas. Têm-se em mão certas ações de pulsões que não puderam a princípio originar prazer, e que "não obstante são repetidas; uma compulsão $(Z$ wang) preme (drängt) a isso"48.

É após essa extensa consideração dos fenômenos contrários ao império do Prazer que Freud diz ter a coragem de supor "que na vida da alma existe efetivamente uma compulsão à repetição (Wiederholungszwang), que se instaura além do princípio de prazer" ${ }^{49}$, e com ela se explicariam não só as repetições infernais dos normais e daqueles em processo transferencial, mas também os sonhos dos neuróticos traumáticos e a dimensão repetitiva do brincar infantil cuja função não é o ganho de prazer. Tanto mais

\footnotetext{
${ }^{45}$ FREUD, id., 13, nota de rodapé.

${ }^{46}$ FREUD, id., 16-20.

${ }^{47}$ FREUD, id., 20-1.

${ }^{48}$ FREUD, id., 20.

${ }^{49}$ FREUD, id., 21.
} 
porque essa Wiederholungszwang se apresenta como "mais original, mais elementar e mais pulsional do que o princípio de prazer por ela posto de lado" ${ }^{50}$.

Ora, o que faz Freud após identificar essa atividade originária da alma de repetir e repetir e repetir inclusive e sobretudo os eventos o mais terrivelmente penosos? Ele parte para a especulação, uma "especulação amiúde muito prolixa" ${ }^{51}$, cujo objeto será o ser vivo em sua elementaridade, em seu funcionamento básico, isto é, que tratará da vida enquanto tal.

É a questão da consciência que será primeiro abordada por Freud. Ela não pode ser uma característica universal dos processos psíquicos e, em verdade, mostra estar vinculada à função perceptiva do organismo. Tornam-se conscientes certas percepções advindas do exterior e certas estimulações advindas do interior, traduzidas em sensações de prazer ou desprazer, fato que impele Freud a afirmar que a consciência "deve jazer no limite entre fora e dentro, estar voltada ao mundo externo e encobrir os outros sistemas psíquicos" ${ }^{52}$. Essa natureza fronteiriça da consciência é de extrema importância, pois é ela, o "seu choque imediato com o mundo externo" (sein unmittelbares Anstoßen an die Außenwelt), que explica uma sua singularidade: a consciência é apta a receber os estímulos externos, mas não sofre nenhuma alteração nesse processo. Na consciência não se registram marcas do contato com o Real; essas marcas se alojam nos sistemas psíquicos envolvidos, revestidos por ela, os sistemas mnêmicos.

E é então que Freud vai do alto ao baixo, do céu da consciência à terra da vesícula indiferenciada (undifferenziertes Bläschen), a manifestação da vida em sua maior simplicidade. Qual o atributo principal desse organismo rudimentar? Ele é uma substância capaz de receber estímulos (reizbar), e é aqui que a especulação freudiana realmente alça voo: lança-se mão da hipótese de acordo com a qual o sistema nervoso proviria da ectoderme, e o córtex cerebral seria um rebento da superfície primitiva e teria recebido por herança os atributos dela. O que teria feito, então, a consciência se diferenciar? Muito precisamente "o incessante choque (Anprall) dos estímulos externos na superfície dessa vesícula”, com o qual uma mudança permanente se teria originado nos diversos estratos do sistema nervoso; uma casca (Rinde) se teria formado, "que finalmente está tão queimada através da influência dos estímulos, que ela demonstra as mais favoráveis circunstâncias para a recepção de estímulos e não é mais apta a uma modificação ulterior" ${ }^{53}$.

A consequência é que, se o organismo "não fosse dotado de uma proteção (contra os) estímulos (Reizschutz)", ele teria sido morto a pancadas (erschlagen werden) pela ação dos estímulos que provêm do mundo externo no meio do qual ele paira e que é "carregado com

\footnotetext{
${ }^{50}$ FREUD, id., 22.

${ }^{51}$ FREUD, id., 23.

${ }^{52}$ FREUD, ibid.

${ }^{53}$ FREUD, id., 25.
} 
as mais potentes energias" 54 . Esse Reizschutz é fundamental para a sobrevivência do organismo rudimentar, ele filtra a energia que o flagela e impede que a sobrecarga energética danifique ou mesmo fulmine as camadas internas de seu sistema nervoso. Ele é “a superfície mais externa” do ser vivo, que nesse ínterim se tornou "em alguma medida inorgânico" "55: "a camada externa por meio de sua morte poupou as internas de passar por um destino igual" ${ }^{56}$. Eis, pois, a primeira aparição da morte na economia freudiana da vida: para que não morresse totalmente, a vida morreu parcialmente, e por isso o orgânico conserva em si um estrato inorgânico mediante o qual ele se protege da opressão esmagadora do inorgânico.

Mais de dez páginas adiante, ao abordar de frente a questão da origem da vida, Freud recorre a uma hipótese muito similar: no início tudo era inanimado e inorgânico, e foi somente por meio da assídua e determinante estimulação externa que o animado e orgânico pôde surgir. Tratar-se-ia de uma espécie de sobrecarga do tecido orgânico, que ato contínuo se esforçaria por descarregá-la, de acordo com o princípio de constância; tal seria a origem da primeira pulsão ${ }^{57}$ (argumento ao qual ainda voltaremos). O importante a reter aqui é que, tanto no caso do Reizschutz (e da consciência) quanto no da vida enquanto tal, é por meio da ação do fora que as mudanças mais essenciais ocorrem.

Ora, há um caso em que a proteção propiciada pela camada mais externa do organismo, isto é, pelo inorgânico no orgânico não é suficiente. Há momentos em que certas "excitações de fora” são "suficientemente fortes para perfurar o Reizschutz", merecendo o nome de traumáticas. O que faz o trauma? Causa "certamente uma enorme perturbação (Störung) na economia energética do organismo e põe todos os meios defensivos em movimento". Consequência: "por isso, contudo, num primeiro momento o princípio de prazer é abolido (ist... außer Kraft gesetzt)" 58 . O organismo sofre uma tamanha inundação de estímulos, que eles não podem ser prontamente tramitados e se faz mister, antes, executar uma outra tarefa, a sua condição de possiblidade: "dominar (bewältigen) o estímulo, ligar psiquicamente as quantidades de estímulos que irromperam" ${ }^{59}$. É por isso que o trauma retorna sem cessar no sonho: ele se repete porque a energia ainda não foi ligada, não foi dominada para em seguida ser tramitada sob a égide do Prazer.

Notemos, pois, que três das características essenciais à vida para o Freud de 1915 se encontram ainda presentes em 1920: para o organismo há uma diferenciação entre o fora e o dentro, ambos lhe são duas origens distintas de estímulos (verdadeiras pancadas, choques ou golpes), e sua tarefa é superá-los, dominá-los (bewältigen). Assim, a

\footnotetext{
${ }^{54}$ FREUD, id., 26.

${ }^{55}$ FREUD, ibid.

${ }^{56}$ FREUD, id., 27.

${ }^{57}$ FREUD, id., 40.

${ }^{58}$ FREUD, id., 29.

${ }^{59}$ FREUD, ibid.
} 
Reizbewältigung, função primal da alma em 1915, permanece sendo a tarefa primordial do organismo em 1920, porém essa superação dos estímulos não é equivalida ao ganho de prazer e evitação de desprazer. Freud postulou algo anterior ao império do Prazer, que lhe é, ademais, condição lógica e ontológica de possibilidade, a necessidade (manifestada na compulsão à repetição) de ligar o excedente energético.

A vida começaria desprotegida, sem o Reizschutz, sua camada mais exterior tornada inorgânica e protetora via queimação repetitiva e incessante. Em seus exórdios, a vida sofreria uma sobrecarga descomunal da energia advinda do mundo externo; em outras palavras, o início da vida seria, para Freud, muito propriamente um trauma. A concepção freudiana de vida é uma concepção traumática: o orgânico é essencialmente a reação a um trauma do inorgânico ${ }^{60}$. O trauma pode não constar como causa primeira da neurose, mas ele está na origem de algo muito mais fundamental: a própria vida. Vê-se, pois, que Freud só pôde incorporar em sua teoria os fenômenos que contrariavam o princípio de prazer (utilizando como paradigma o conceito de trauma) ao abordar de frente os dois pontos de tensão que diagnosticamos em 1915: os problemas do estatuto da realidade e da origem da vida.

E é tanto a respeito da origem da vida quanto do seu dinamismo essencial que o conceito de pulsão será redefinido. Redefinido, porém não totalmente, pois as pulsões são mais uma vez apresentadas como "os representantes de todos os efeitos de forças (Kraftwirkungen) que provêm do interior do corpo e se transferem ao aparelho psíquico"61, forças estas ante as quais nenhum Reizschutz é eficaz. A pergunta que se faz Freud vai no sentido de incorporar a compulsão à repetição (uma atividade anímica mais elementar e mais pulsional, não nos esqueçamos) à teoria das pulsões: "de que modo, contudo, o pulsional se relaciona com a compulsão à repetição?” A resposta concerne não apenas à natureza da pulsão, mas também da vida enquanto tal - "uma pulsão seria, assim, um esforço (Drang), imanente ao orgânico vivo, de reestabelecimento de um estado anterior, ao qual o ser vivo teve de renunciar sob a influência de forças perturbadoras externas" ${ }^{2}$, sendo a pulsão então caracterizada como uma espécie de elasticidade ou de inércia do orgânico. E Freud segue seus pressupostos de base e suas hipóteses até as últimas

\footnotetext{
${ }^{60}$ Não somente um trauma, pois que a persistência da vida, como veremos, depende da insistência dessa sobrecarga energética advinda do fora; ou seja, o viver da vida depende de fluxos temporais de energia. $\mathrm{O}$ trauma seria, assim, um golpe singular, mas que, insistindo temporalmente a partir do fora, seria interiorizado, passando a se tornar a força constante que Freud denomina pulsão. Lembremos que também Laplanche reconduz ao trauma a questão da vida em Freud, ao comentar o Além do Princípio do Prazer. "todo ser vivo aspira à morte em razão de sua tendência interna mais fundamental, e a diversidade da vida, tal como a observamos em suas formas múltiplas, nunca faz mais que reproduzir uma série de avatares fixos ao longo da evolução, desvios adventícios provocados por este ou aquele traumatismo" (LAPLANCHE, Vida e morte em psicanálise, 110).

${ }^{61}$ FREUD, Jenseits des Lustprinzips, 35.

${ }^{62}$ FREUD, id., 38.
} 
consequências: dada essa situação inaugural da vida, seria ilógico supor que, no processo vivente, ela poderia almejar um estado pelo qual não houvesse antes passado. Tudo o que a vida pode fazer é tentar e buscar repetir um estado de coisas anterior. Ora, o estado de coisas mais primário, o Ausgangszustande, não pode ser, no limite, senão a própria morte. A conclusão, em se supondo que o vivo só pode morrer por motivos internos, é que "o objetivo (Ziel) de toda vida é a morte, e retrospectivamente: o sem-vida (das Leblose) esteve aí antes do vivente (das Lebende)"63.

O objetivo, o fim (Ziel) da vida é também o seu início, o seu ponto de partida (Ausgang). A questão toda se centra no sufixo alemão (que já vimos em 1915 a respeito de um possível estado isento de excitação) -los do Leblose. A vida é um erro da morte, e das Lebende se encontra sempre em descompasso com das Leblose do qual se originou. Eis a essência da concepção freudiana de vida expressa na diferença sintática que carregam os dois termos contrapostos: lebend é particípio presente, indica ação em andamento ("aquele que vive"), enquanto leblos indica um estado, um atributo estático e de referência negativa (“sem vida”). A vida, então, é uma espécie de ação gerundial, um processo incessante que se pauta sempre no seu início e no seu fim, no negativo estático que lhe dá sentido: a morte.

Pode-se dizer, pois, que a vida em Freud é a morte da morte. Eis a morte sendo enxertada na vida de forma positiva, não mais como limite lógico que determinaria e condicionaria a vida negativamente, por fora, mas sim enquanto finalidade última, condição de possibilidade e momento instaurador. A vida seria, assim, uma morte em segunda potência, seria morte da morte, morte de si mesma, e seu objetivo não seria outro senão dar morte à morte da morte. Assim como cada ser vivo é finito e sua existência tem um ponto temporal derradeiro, também a vida em seu conceito mesmo é finita e, ao concretizar sua vocação máxima, deixa de ser aquilo que ela é. Em Freud a vida vive para se extinguir - e nada mais.

Se em 1915 a vida era um ponto pacífico dentro da argumentação e os processos biológicos se desenrolavam sempre, para a psicanálise, sob o enquadramento das "três grandes polaridades”, é possível afirmar que em 1920 Freud não nega a sua tabela de categorias do exercício pulsional, porém conceitua suas condições de possibilidade: a morte da morte que é a instauração da vida é muito precisamente esse evento em que aquele campo de negatividades, num fatídico e inaugural momento, se encontra em suspensão - o trauma. Nele, a diferenciação entre sujeito e objeto está suspensa, assim como as outras duas dualidades lógico-ontológicas; o que era externo se repete incessantemente dentro, e há uma inundação tamanha de estímulos que a atividade do organismo entra em sursis. Essa total passividade é também total atividade, pois é somente então que o organismo é posto em marcha para executar a tarefa de unir psiquicamente o excedente de energia.

${ }^{63}$ FREUD, id., 40. 
A complexidade da vida se torna nesse ponto um enigma, visto que, por princípio, ela obteria sucesso nessa empreitada suicida com muita facilidade: mal se tornara vivo e o organismo já voltaria ao seu estado inanimado. Freud não tem outra saída: foi somente pela insistência da estimulação externa que a vida pôde tornar-se mais e mais complexa, singularizando-se enquanto uma série de "desvios para [atingir] a morte" (Umwege zum Tod) ${ }^{64}$. Mas a complexidade manifesta dos organismos pluricelulares não esconde o essencial do processo vivente: muitos seres vivos se mantiveram em sua estrutura primitiva, são unicelulares e não atingiram a complexidade de animais e plantas; mas, mais do que isso, é notável que as células germinais dos animais sejam assim até hoje, rudimentares e unitárias. A vida, mesmo a mais complexa, se perfaz na geração de novos indivíduos por meio dos quais ela vive, mas isso só se dá a partir da união entre uma célula germinal e outra "parecida consigo e no entanto dela diferente" ${ }^{65}$. A partir dessa união, a que está fadado o novo indivíduo? A repetir toda a história pregressa da espécie. Essas células germinais, potencialmente imortais (unsterblich), ao se fundirem fazem viver a vida, o que significa apenas uma "prorrogação do caminho até a morte" (eine Verlängerung des Todesweges). É isto, portanto, a vida enquanto processo intermitente: uma prorrogação do fim último, a morte. Nesse ciclo se manifesta a contradição que habita imanentemente a vida: o indivíduo (particular), mesmo complexo, começa por uma célula única que repete toda a história pregressa da espécie (universal). Uma parte vai até o fim (a morte), mas uma outra, que lhe é derivada (o plasma germinal), reinicia o jogo infatigável.

Tal série de hipóteses e conclusões excluiria a admissão de qualquer concepção progressista de vida para Freud. Dizer que uma forma de vida é mais evoluída do que outra talvez seja apenas "questão de nossa apreciação" (Sache unserer Einschätzung), e muitas vezes os dados aportam que o que se julga ser uma evolução de parte do tecido vivo se paga com uma involução de outra parte sua. Por isso

tanto o progresso evolutivo quando a regressão poderiam ambos ser consequências de forças externas premendo à adaptação (zur Anpassung drängenden), e o papel das pulsões, em seus dois casos, poderia limitar-se a conservar, como fonte interna de prazer, essas mudanças impostas ${ }^{66}$.

O choque com o Real é, portanto, algo primeiro, muito mais primordial que a regulação pela série prazer-desprazer (como suspeitáramos já em 1915). A pulsão seria a interiorização da compulsão à adaptação ante esse distúrbio a que o organismo está propenso, em seu constante contato com o Real. É por essa interiorização do externo que se explica a existência de pulsões de conservação: pela ação delas o indivíduo evita a todo custo as influências (externas) que encurtariam sua missão imanente (morrer). Mas ele o faz

\footnotetext{
${ }^{64}$ FREUD, id., 40-1.

${ }^{65}$ FREUD, id., 42.

${ }^{66}$ FREUD, id., 44.
} 
somente para concretizá-la ele mesmo: "o organismo quer morrer apenas à sua própria maneira" ${ }^{67}$. Ora, as pulsões sexuais, mediante cuja ação há a união de gametas e o prosseguimento da vida, prorrogam a sobrevida da vida indefinidamente, assim como as pulsões de conservação prorrogam indefinidamente a sobrevida do indivíduo. É por isso que ambas são doravante agrupadas sob a classe maior de pulsões de vida (Lebenstriebe). Contrapostas a elas, postulam-se as pulsões de morte (Todestriebe), que premeriam o organismo à sua anulação total. "Existe como que um ritmo hesitante na vida dos organismos" ${ }^{68}$ : uma parte das pulsões preme para frente, para possibilitar e propiciar o seu fim (a morte), enquanto outra parte delas vai para trás e retoma um estado de coisas anterior, mais simples, em que a morte era objetivo mais fácil, e força a vida a repetir uma vez mais todo o trajeto já percorrido. Há, portanto, séries descompassadas de repetições (para frente e para trás), e é nesse descompasso, nesse ritmo titubeante que tem lugar a vida.

Aqui queda muito patente que uma teleologia muito bem delimitada e delimitadora é entrevista nos processos vitais e pulsionais; mas, mais do que isso, o telos pulsional que assomava marginalmente na argumentação de 1915 é aqui subsumido ao telos maior da vida. A reprodução e a preservação da espécie são apenas uma modalidade do processo teleológico maior, que se manifesta sob a égide da repetição do mesmo. É nesse sentido que "a repetição é, muito precisamente, a condição de possibilidade da pulsão, aquilo sem o qual ela não poderia se re-produzir"69, como diz Mezan, ou, nas palavras de Rechardt, "a grande invenção de Freud em Além do princípio do prazer foi a de ver na repetição a forma básica do trabalho psíquico"70; e é por meio de diversos modos de repetição que o interjogo pulsional (entre pulsões de vida e pulsões de morte) poderá se dar.

A temática da repetição do mesmo aparece de forma vultosa na vida da criança, como Freud expusera poucas páginas antes: ela exige a identidade da brincadeira a ser repetida ou da história a ser recontada; de todo modo, ela requer de forma implacável "a identidade da impressão" (die Identität des Eindruckes), desejando a "repetição, o reencontro da identidade" (die Wiederholung, das Wiederfinden der Identität) ${ }^{71}$. Nesse sentido, tudo o que a pulsão quereria era a repetição desse idêntico, a repetição de uma primeira vivência de satisfação, mas o que ela consegue, em virtude da sua natureza mesma, são apenas substitutos mais ou menos similares a ele. Como vimos, essa repetição total vem sob a forma da alucinação, que, por ser inapta a realmente amainar a estimulação interna, tem de ser abandonada pelo organismo. "Da diferença entre o prazer de satisfação encontrado e o exigido resulta o fator pulsionante (das treibende Moment), que não se

\footnotetext{
${ }^{67}$ FREUD, id., 41.

${ }^{68}$ FREUD, id., 43.

${ }^{69}$ MEZAN, Freud: a trama dos conceitos, 258.

${ }^{70}$ RECHARDT, Os destinos da pulsão de morte, 49.

${ }^{71}$ FREUD, id., 36-7.
} 
permite permanecer em nenhuma das situações estabelecidas"72. A vida é esta impossibilidade mesma de repetir o idêntico enquanto tal, a vida é esse malogro, esse erro, essa falha da matéria inorgânica; seu destino é, pulando de diferença em diferença, almejar atingir o Idêntico. Ora, é justamente por essa missão ser impossível que a vida persiste enquanto ação gerundial, enquanto lebend, para, ao cumpri-la, tornar-se lebenlos e deixar de ser o que é. É somente ao se concretizar às metades, claudicante e titubeante, que a vida pode viver. Quando a vida alcança totalmente o que ela quer, ela morre e passa ao seu negativo absoluto. A morte não pode ser então algo gratuito - ela é conquistada a duras penas, sob o pagamento da dissolução do próprio conceito de vida, a partir mesmo de sua concretização teleológica absoluta.

\section{IV}

Como vários autores diagnosticaram, é a repetição a figura maior das argumentações de Freud em $1920^{73}$. É em torno dela que o império do princípio de prazer será questionado, é com ela que se define a essência mesma da pulsão. Essa essência da ação pulsional, porém, inscreve-se muito explicitamente num horizonte muito bem definido, um horizonte teleológico por excelência, em que um fim para toda a atuação pulsional é preestabelecido: a própria cessação dessa atuação, a morte mesma.

Entretanto, como fizemos notar, uma teleologia se inscrevia na teoria freudiana das pulsões já antes de 1920. Não deixa de ser eloquente a adição de uma nota de rodapé aos seus Três ensaios sobre a teoria sexual justamente em 1920 a esse respeito: "dificilmente se consegue evitar, em considerações biológicas, servir-se da maneira teleológica de pensar"74. Parece-nos mesmo que a dimensão da causa final faz parte constituinte das argumentações freudianas, ou seja, parece-nos que para Freud à dimensão da vida faz parte necessariamente um horizonte teleológico. Em 1915, essa teleologia é afirmada enquanto função de reprodução: neste caso, trata-se da repetição do universal (espécie) em detrimento do particular (indivíduo), isto é, do idêntico em detrimento do diverso. Embora essa teleologia apareça marginalmente, ela surge repetidas vezes nos textos mais teóricos de Freud, marcando presença nos Três ensaios, em seu artigo de 1914 sobre o narcisismo, em Pulsões e destinos da pulsão, no Além do Princípio e n'O eu e o isso ${ }^{75}$..., apenas para

\footnotetext{
${ }^{72}$ FREUD, id., 44-5.

${ }^{73}$ Já mencionamos Mezan e Rechardt; agreguemos, a título de exemplo, também Deleuze ("a pulsão de morte é descoberta, não em relação com as tendências destrutivas, não em relação com a agressividade, mas em função de uma consideração direta dos fenômenos de repetição”, Différence et Répétition, 27) e Laplanche ("os fenômenos mais variados da repetição, naquilo que eles têm de irredutível, são considerados como a essência da pulsão", Vida e morte em psicanálise, 110).

${ }^{74}$ FREUD, Drei Abhandlungen zur Sexualtheorie, 85, nota de 1920.

${ }^{75}$ Neste caso, especialmente no último parágrafo de sua quarta seção (Die beiden Triebarten).
} 
elencar alguns. Negar essa teleologia em Freud, teleologia imanente à vida, é negar uma parcela fundamental de sua teorização.

Nessa teleologia vital já se apresenta também a morte: o múltiplo e diferente (o indivíduo) pode e deve perecer, contanto que o mesmo e uno (a espécie) subsista e se reproduza. No entanto essa aparição é lateral. Somente em 1920 o estatuto da morte mudará, e ela fará parte da dinâmica incessante da vida. Citemos aqui Laplanche: se de início "a vida [...] está presente, materialmente, nas fronteiras da psiquê, a entrada em cena da morte é muito mais enigmática”. É só “mais tarde, em 1920, que ela aparece no centro do sistema, como uma das duas forças fundamentais e talvez mesmo como a única força primordial no centro do psiquismo, do ser vivo e até mesmo da matéria"76. Assim, como pensamos poder ter demonstrado, não é que a concepção freudiana de vida tenha em 1920 sofrido uma imensa reviravolta; ela em linhas gerais permaneceu a mesma e foi levada às suas últimas consequências. O que mudou nesse ínterim foi o estatuto da morte dentro dessa concepção, que de limite externo e negativo passou a ser origem, finalidade e momento instaurador. Às três grandes dualidades esmiuçadas em 1915 (eu - mundo externo; dentro-fora, sujeito-objeto), antepõe-se uma dualidade mais primal: vida-morte.

Essa incorporação da morte no seio da vida não se deu, porém, no vazio. A releitura que fez Freud de seu conceito de pulsão se deu, de um lado, através da consideração de fatos clínicos e fenômenos observáveis e, por outro, através da consideração de constatações teóricas já presentes em suas argumentações prévias (a importância do Real e a questão da origem da vida). As condições dessa releitura da sua doutrina pulsional já estavam, portanto, inscritas em sua teoria mesma.

Isso nos faz reafirmar os resultados da análise de Monzani, que nos quatro capítulos de seu livro sobre Freud ${ }^{77}$ desconstruiu a noção categórica de "ruptura" para caracterizar as reformulações presentes em sua obra. Esperamos com este texto ter contribuído para a compreensão do modo com que Freud, em seu pensamento em forma de "espiral e pêndulo", acaba por se debruçar sobre questões antigas, semelhantes e repetitivas, para repensá-las e reelaborá-las tantas e tantas vezes.

\section{Referências}

DELEUZE, Gilles. Différence et Répétition. Paris : PUF, 1968.

FREUD, Sigmund. Die Traumdeutung. In: Gesammelte Werke, Band 2-3. Frankfurt am Main: Fischer Verlag, 1999

FREUD, Sigmund. Drei Abhandlungen zur Sexualtheorie. In: Gesammelte Werke, Band 5. Frankfurt am Main: Fischer Verlag, 1999

\footnotetext{
${ }^{76}$ LAPLANCHE, Vida e morte em psicanálise, 13.

${ }^{77}$ MONZANI, Freud: o movimento de um pensamento.
} 
FREUD, Sigmund. Formulierungen über die zwei Prinzipien des psychisches Geschehens. In: Gesammelte Werke, Band 8. Frankfurt am Main: Fischer Verlag, 1999

FREUD, Sigmund. Einige Bemerkungen über den Begriff des Unbewussten ind der Psychoanalyse. In: Gesammelte Werke, Band 8. Frankfurt am Main: Fischer Verlag, 1999

FREUD, Sigmund. Zur Einführung des Narzissmus. In: Gesammelte Werke, Band 10. Frankfurt am Main: Fischer Verlag, 1999

FREUD, Sigmund. Triebe und Triebschicksale. In: Gesammelte Werke, Band 10. Frankfurt am Main: Fischer Verlag, 1999

FREUD, Sigmund. Die Verdrängung. In: Gesammelte Werke, Band 10. Frankfurt am Main: Fischer Verlag, 1999

FREUD, Sigmund. Das Unbewusste. In: Gesammelte Werke, Band 10. Frankfurt am Main: Fischer Verlag, 1999

FREUD, Sigmund. Metapsychologische Ergänzung zur Traumlehre. In: Gesammelte Werke, Band 10. Frankfurt am Main: Fischer Verlag, 1999

FREUD, Sigmund. Trauer und Melancholie. In: Gesammelte Werke, Band 10. Frankfurt am Main: Fischer Verlag, 1999

FREUD, Sigmund. Jenseits des Lustprinzips. In: Gesammelte Werke, Band 13. Frankfurt am Main: Fischer Verlag, 1999

FREUD, Sigmund. Das Ich und das Es. In: Gesammelte Werke, Band 13. Frankfurt am Main: Fischer Verlag, 1999

FREUD, Sigmund. Die Verneinung. In: Gesammelte Werke, Band 14. Frankfurt am Main: Fischer Verlag, 1999

FREUD, Sigmund. Die Ichspaltung im Abwehrvorgang. In: Gesammelte Werke, Band 17. Frankfurt am Main: Fischer Verlag, 1999

GARCÍA-ROZA, Luiz Alfredo. Freud e o inconsciente. Rio de Janeiro: Jorge Zahar Editor, 2009.

HANNS, Luiz. Dicionário comentado do alemão de Freud. Rio de Janeiro: Imago, 1996.

LAPLANCHE, Jean. Vida e morte em psicanálise. Porto Alegre: Artes Médicas, 1985.

MEZAN, Renato. Freud: A trama dos conceitos. São Paulo: Perspectiva, 1982

MONZANI, Luiz Roberto. Freud: O movimento de um pensamento. Campinas: Editora da Unicamp, 1989

RECHARDT, Eero. Os destinos da pulsão de morte. In: A pulsão de morte (André Green et al.). São Paulo: Escuta, 1988

SAFATLE, Vladimir. A teoria das pulsões como ontologia negativa. Revista Discurso, São Paulo, n. 36, 2007, pp. 149-189 